\title{
Ergonomic Evaluation of Hand Operated Maize Sheller for Reducing Drudgery of Farm Women in Bihar
}

\author{
BIKASH SARKAR, PREM K SUNDARAM*, AP ANURAG, RAKESH KUMAR,UJJWAL KUMAR, \\ A RAHMAN AND AUPADHYAYA
}

\begin{abstract}
Maize shelling is one of the tedious and time-consuming agricultural operations. To reduce the drudgery of farm women involved in maize shelling, a hand-held octagonal maize sheller (OMS) tool was introduced. The OMS tool was evaluated for its impact on human health and shelling efficiency. An ergonomic study of the OMS tool was carried out with farm women as subjects for evaluation. Various ergonomic and technical performance parameters were assessed for two types of shelling viz. hand shelling and shelling using OMS tool. The results revealed that the OMS tool and hand shelling recorded an output of 23.71 and $8.87 \mathrm{~kg} / \mathrm{h}$, respectively. The cardiac cost per unit of output worked out was 69.73 and 287.09 beats $/ \mathrm{kg}$ for OMS tool and hand shelling, respectively. Compared to hand shelling, the OMS tool reduced drudgery by $75.71 \%$. Overall discomfort rating was 1.58 and 2.12 while the body part discomfort score was 21.27 and 30.41 for OMS tool and hand shelling, respectively. Adoption of OMS tool reduced the physical stress as very small percentage of subjects $(<40 \%)$ reported about the body pain. In view of increased shelling efficiency and reduced physical pain, the OMS tool was found more suitable and is recommended for maize shelling.
\end{abstract}

KEYWORDS

Ergonomic, Drudgery, Cardiac cost, Discomfort Score, Maize shelling

\begin{tabular}{lll}
\multicolumn{2}{c}{ ARTICLE INFO } \\
\hline Received on & $:$ & $21 / 11 / 2020$ \\
Accepted on & $:$ & $18 / 02 / 2021$ \\
Published online & $:$ & $19 / 03 / 2021$ \\
\hline
\end{tabular}

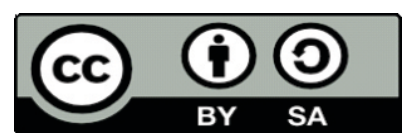

\section{INTRODUCTION}

$\mathrm{I}$ n India, maize (Zea mays L.) is the third most important cereal crop after rice and wheat (Singh et al., 2017). Maize crop is utilized at the global level as staple food $(17 \%)$, as feed $(61 \%)$ and industrial purposes $(22 \%)$. However, in India it is largely used for poultry feed (51\%) followed by starch food $(23 \%)$ and cattle feed (12\%). In India maize is grown in all the seasons, i.e., kharif, rabi and summer. In Bihar, maize is cultivated on 7.12 lakh hectares of land with production of 28.20 lakh ton. The productivity in the state is much higher (3.98 t/ha) than that of national average of $2.5 \mathrm{t} /$ ha (Kumar et al., 2005). After harvesting maize with sickle and plucking of cob manually, de-husking of cob is carried out by hand to remove its outer sheath. Maize grains are obtained by shelling of the cob using traditional manual methods like beating the dehusked cobs with sticks, using fingers or sickle for shelling of individual cob etc. This activity is mostly done by farm women and output varies with individual skills. A few authors reported on performance of hand shelling and octagonal maize sheller. Singh et al., (2010) reported the shelling efficiency of tubular maize sheller as $26 \mathrm{~kg} / \mathrm{h}$ as against $13 \mathrm{~kg} / \mathrm{h}$ in hand shelling. In another study, Tripathi et al. (2016) found that the octagonal maize sheller saves almost half the time and increases working efficiency by $79.24 \%$ and reduces drudgery of farm women by $87.94 \%$ over traditional practice of hand shelling. The cleaning efficiency was also found to increase by $6.6 \%$. The maize

ICAR-Research Complex for Eastern Region, Patna, Bihar, India *Corresponding author email : prem.k.sundaram@gmail.com sheller shelled $28.4 \mathrm{~kg} / \mathrm{h}$ as compared to sickle 18.7 $\mathrm{kg} / \mathrm{hr}$. with increase efficiency $34 \%$ for maize crop (Verma et al., 2016). The output in terms of de-huskingshelling maize cobs was reported to be $30 \mathrm{~kg} / \mathrm{h}$ with $8.3 \%$ grain damage in the traditional system: de-husking by hand and shelling by beating wooden sticks (Singh et al., 2011).

Various studies on women in agriculture point to the fact that women are generally employed in the operations, which are either not mechanized or least mechanized and involve a lot of drudgery (Singh et al., 2007). Tripathi et al. (2016) have reported the significant role of women in Indian agricultural sector and have also mentioned that more than 75 per cent women are involved in activities like winnowing, weeding, grading, threshing and cleaning of field farm operations. Threshing or shelling is the most tedious and time-consuming job (Meyers et al., 1997). Previous research showed that manual maize shelling is very exhausting and time-consuming task and the fingers and palm of farm women are generally injured during traditional hand shelling which reduces the efficiency of farm women. Therefore, there is an urgent need to study the possible tools that can save time, increase efficiency and reduce the drudgery of the farm women. The present study was undertaken with the twin objectives of introducing a new OMS tool to minimize the drudgery and increase the efficiency of farm women in maize shelling and also compare hand shelling and shelling with OMS tool ergonomically. 


\section{MATERIALS AND METHODS}

Ergonomic evaluation of maize shelling by manual hand shelling and OMS tool methods was carried out with farm women at ICAR RCER, Patna during 9-22 May 2019. The maize cobs used for the study were harvested from institute farm. The cobs were allowed to dry for few days and at the time of experimentation the moisture content and the cobkernel ratio of the cobs was $9.76 \%$ and $1: 3.67$, respectively.

\section{Octagonal Maize Sheller (OMS)}

An OMS is a tool used to separate maize grains from dehusked cobs. The maize sheller used for conducting the study was of octagonal shape. It had four mild steel fins tapered along their length with one of the edges of fin tapered Fig.1 (a). Two holes are made on each fin for the purpose of riveting. In order to assemble the maize sheller in an octagonal shape, each fin was bent at two places. Care was also taken for providing safety aspect by bending the fins, thereby avoiding injury during operation. The maize sheller is generally made of sheet metal and in order to increase its working life and avoid corrosion, it is powder coated. As shown in Fig.1 (b), the de-husked maize cob is held in the right hand and OMS in the left. The cob is given clockwise and anti-clockwise movement by inserting the de-husked maize cob in the OMS leading to separation of grains from the cob. After removing the grains from one side of the cob, other side is inserted into the sheller for complete removal of grains from the cob.

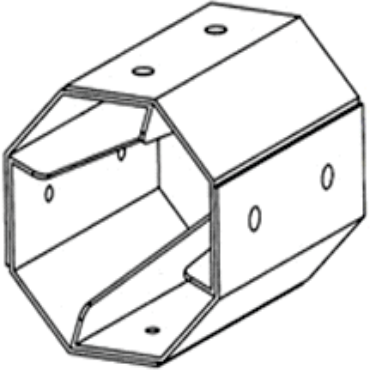

Fig.1(a): Maize Sheller

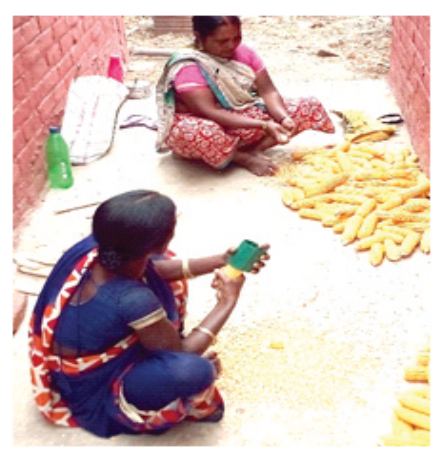

Fig.1(b): Operational view of octagonal maize sheller
Selection of subjects

Ten farm women with no history of acute or chronic illness or cardio vascular diseases were randomly selected for the experiment in which they had to wear a belt (Polar HR monitor) and perform maize shelling by hand shelling and OMS tool (Fig.1(b). The age of participating women ranged between 35-55 years and they had no physical disability. The shelling capacity of both the methods was calculated by noting the time required for shelling of 100 cobs $(14.26 \mathrm{~kg})$. The anthropometric rod and weighing balance were used to measure the physical characteristics like height and weight of the participating farm women. The health status of women was graded on the basis of Body Mass Index (BMI). The BMI was calculated as per the procedure given by Garrow (1987). Stop watch was used for recording the time while the heart rate was recorded using the polar heart rate monitor. During experimental period, the air temperature varied between 22$40^{\circ} \mathrm{C}$ with an average relative humidity of $48 \%$. In manual maize shelling by hand, agricultural worker removes the grain from cob by using their thumb. First, they separate a line of grain and after that they rub the cob by another shelled cob in order to remove the grains. Due to rubbing action grains get separated from the cobs. The operations were done in sitting posture.

\section{Work output parameters}

Generally, heart rate is used as an ergonomic measure to evaluate the physiological or functional demands of work on the individual workers (Hasalkar et al., 2004). The heart rate is a better index of the overall physiological demand of work than energy expenditure and it has the additional advantage of being very easy to measure in the field. Several research workers (Singh et al., 2007; Singh and Gite, 2007) have used heart rate for assessment of the physiological workload of the workers. Polar Heart Rate Monitor (Model-RS 400) was used for recording the heart rate of subjects and stopwatch was used for recording the time consumed. Based on the heart rate records the parameters like change in heart rate at rest and during work $(\triangle \mathrm{HR})$, energy expenditure (EE) (Varghese et al.,1994), output (Op), cardiac cost per unit of output (CC) and oxygen consumption (OC) (Singh et al., 2008) were determined for each subject.

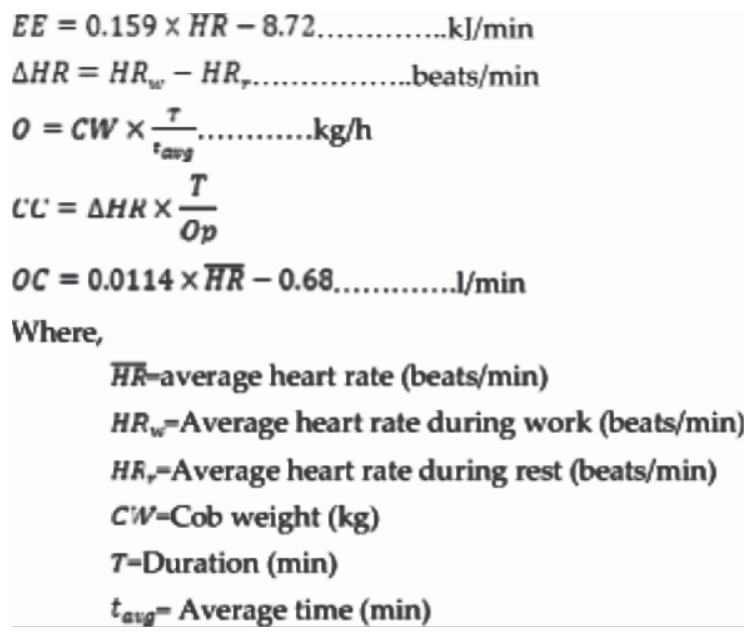

Where,

The lean body mass (LBM) of the subjects was estimated as per Humes (1966) and the body surface area, $\mathrm{m}^{2}$ (BSA) was estimated as per Schlich et al.(2010).

\section{$L B M=(0.29569 \times B W)+(0.41873 \times B H)-43.2933$ \\ $B S A=0.000975482 \times B W^{0.46} \times B^{106}$}

Where,

$\mathrm{BW}=$ body weight of the subject $(\mathrm{kg})$

$\mathrm{BH}=$ body height of the subject $(\mathrm{kg})$

\section{Physiological stress}

Overall Discomfort Rating/Score and Body Part Discomfort Score (BPDS) are subjective method of quantification of physiological stress or body pain. 


\section{Overall discomfort Rating/Score (ODR/ODS)}

The assessment of overall discomfort scores was carried out on a 5-point rating scale (1-no discomfort, 5-extreme discomfort). This method was developed by Corlett and Bishop (1976). The overall discomfort rating (ODR) of the farm women were measured by using a 5-point scale having 1 to 5 digits marked from left to right on it (1- No Tiredness, 2-Slightly tired, 3Tired, 4- Very Tired and 5- Extremely Tired) (Potdar et al.,2011).

\section{Body Part Discomfort Score (BPDS)}

Body part discomfort score (BPDS) is a score-based technique (Corlett and Bishop, 1976), in which the subject's body is divided into 27 regions (Fig. 2). Subjects were asked to indicate their assessment of discomfort in each region. Each subject was asked to mention all body parts with discomfort, starting with the most painful, in descending order till all the body parts experiencing discomfort had been recorded. The number of different groups of body parts, which were identified from extreme discomfort to no discomfort, represented the intensity of discomfort experienced by a

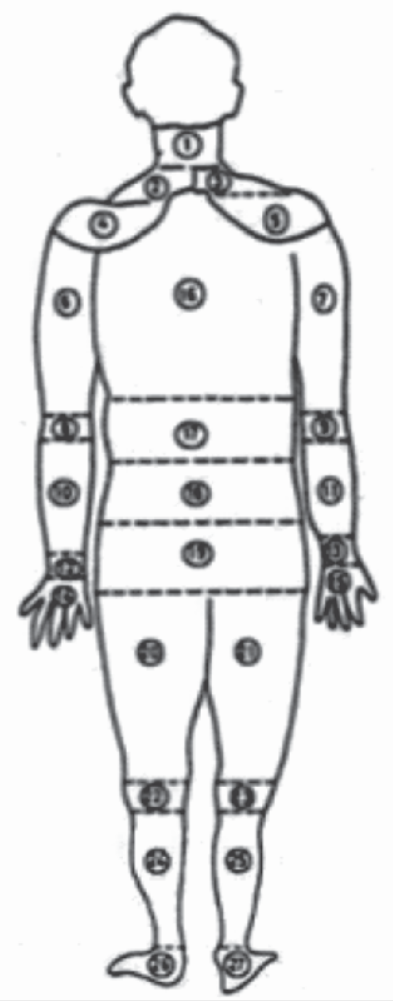

Fig 2: Body map for Body Part Discomfort Score (BPDS)

Table 1: Physical characteristics of selected respondents $(\mathrm{N}=10)$

\begin{tabular}{lc}
\hline Physical characteristics & Mean \pm S.D. \\
\hline Age (Yrs.) & $44.90 \pm 5.84$ \\
Height $(\mathrm{cm})$ & $151.20 \pm 5.63$ \\
Weight $(\mathrm{kg})$ & $47.38 \pm 10.23$ \\
BMI & $20.78 \pm 4.83$ \\
Body surface area $\left(\mathrm{m}^{2}\right)$ & $1.29 \pm 0.14$ \\
Lean Body Mass $(\mathrm{kg})$ & $34.03 \pm 3.99$ \\
\hline
\end{tabular}

subject. The intensity levels of discomfort were categorized in groups, and were assigned a numerical value to each group. The body part discomfort score is the product of multiplication of number of body parts and numerical rating assigned to each category.

\section{RESULTS AND DISCUSSION}

Randomly selected healthy women farm workers had age in the range of 35-50 years with an average age of 44.90 years (Table 1). The average height and weight of workers was $151.20 \mathrm{~cm}$ and $47.38 \mathrm{~kg}$, respectively. The average BMI was found to be 20.78 which indicate that the farm workers involved in the experiment were fit and healthy. Average lean body mass was found to be $34.03 \mathrm{~kg}$. Physiological stress experienced while working on maize sheller was determined on the basis of various parameters like average heart rate during work and rest, energy expenditure and physiological cost of work while shelling. On an average, hand shelling required 99 minutes whereas OMS tool required only 30 minutes to shell 100 maize cobs (Table 2). The cob-kernel ratio, moisture content and shelling capacity were 1:3.67, 9.76 \% and $23.83 \mathrm{~kg} / \mathrm{h}$, respectively. The output of OMS tool was $23.71 \pm 1.39 \mathrm{~kg} / \mathrm{h}$ while for hand shelling it was $8.87 \pm 1.89 \mathrm{~kg} / \mathrm{h}$. These results are in conformity with to Singh et al., (2010), who reported an output of $26 \mathrm{~kg} / \mathrm{h}$ for octagonal maize sheller as against $13 \mathrm{~kg} / \mathrm{h}$ by hand shelling. During hand shelling, the average change in heart rate $(\Delta \mathrm{HR})$ was 12 beat $/ \mathrm{min}$ while for OM Stool, it was recorded as $15.76 \mathrm{beat} / \mathrm{min}$. The cardiac cost of worker was 287.09 beats/ $\mathrm{kg}$ during manual shelling while it was only 69.73 beats $/ \mathrm{kg}$ for OMS tool. This indicates that the OM Stool saved $75.71 \%$ cardiac cost of worker per unit of output. Energy expenditure was $5.27 \mathrm{~kJ} / \mathrm{min}$ for hand shelling whereas, it was $6.98 \mathrm{~kJ} / \mathrm{min}$ for OMS tool, thereby recording an overall increased efficiency of $24.49 \%$.The energy expenditure estimates were well within the criteria given by Nag and Chatterjee, 1981.Tripathi et al. (2016) reported similar trend with octagonal maize sheller, which saves almost half the time and increases working efficiency $79.24 \%$ and reduces $87.94 \%$ drudgery of farm women over traditional practice.

Table 2: Ergonomic evaluation data of different parameters during maize shelling $(\mathrm{N}=10)$

\begin{tabular}{l|cc}
\hline Particulars & \multicolumn{2}{|c}{ Mean values \pm S.D } \\
\cline { 2 - 3 } & Hand Shelling & $\begin{array}{c}\text { Octagonal } \\
\text { Maize Sheller }\end{array}$ \\
\hline $\begin{array}{l}\text { Number of workers required } \\
\text { Time spent to shell 100 cobs }\end{array}$ & 01 & 01 \\
*min.) & $99 \pm 3.6$ & $30 \pm 4.64$ \\
Average working heart rate & $88.00 \pm 5.28$ & $98.76 \pm 14.31$ \\
(beats/min) & & 15.76 \\
Average heart rate during rest & $76.00 \pm 8.04$ & $23.71 \pm 1.39$ \\
(beats/min) & & 69.73 \\
$\begin{array}{l}\text { (bR (beats/min) } \\
\text { Output (kg/hr) }\end{array}$ & 12 & 6.98 \\
Cardiac cost (beats/kg) & $8.87 \pm 1.89$ & 75.71 \\
Energy expenditure, $\mathrm{kJ} / \mathrm{Min}$ & 287.09 & 5.27 \\
Reduction in drudgery, \% & - & \\
\hline
\end{tabular}

${ }^{*}$ wt. of 100 cobs is approximately $14.50 \mathrm{~kg}$ for both the treatments 
The physiological difference was also observed by previous research workers (Singh and Gite, 2007; Singh et al., 2010) during various agricultural operations. The oxygen consumption rate (OCR) of women workers was estimated at $0.32 \mathrm{l} / \mathrm{min}$ during hand shelling and $0.45 \mathrm{l} / \mathrm{min}$ during shelling by OMS tool.

The aerobic capacity was estimated as $24.37 \%$ and $33.61 \%$ for manual and OMS, respectively. The OCR was also found within the acceptable limit of $40 \%$ of aerobic capacity (Nag and Chatterjee, 1981). Normal rest pauses may be provided to the workers for day long operation as heart rate and oxygen consumption rate values are within the acceptable limit. Overall discomfort rating was calculated as 1.58 and 2.12 for working with OMS tool and hand shelling respectively. Body part discomfort score was 21.27 and 30.41 for OMS tool and hand shelling, respectively. Values of all the metrics like heart rate, work pulse and energy expenditure rate were within acceptable limits indicating that OMS tool was more suitable for the farm women engaged in maize shelling.

Working efficiency and productivity is affected by the occurrence of health hazards in any farm activity. Hand pain, figure injury and palm injury were prominent forms of pain that farm women experienced in maize shelling by hand. Table-3 reveals that in case of hand shelling larger

Table 3: Comparison of health hazards in manual and octagonal maize shelling

\begin{tabular}{l|cccc}
\hline \multirow{2}{*}{ Health Hazards } & \multicolumn{2}{|c}{ Manual shelling } & \multicolumn{2}{c}{ Octagonal maize sheller } \\
\cline { 2 - 5 } & Yes & No & Yes & No \\
\hline Hand Pain & $70 \%$ & $30 \%$ & $40 \%$ & $60 \%$ \\
Shoulder Pain & $40 \%$ & $60 \%$ & $20 \%$ & $80 \%$ \\
Backache & $30 \%$ & $70 \%$ & $30 \%$ & $70 \%$ \\
Waist pain & $10 \%$ & $90 \%$ & $10 \%$ & $90 \%$ \\
Finger injury & $70 \%$ & $30 \%$ & NA & $100 \%$ \\
Palm injury & $80 \%$ & $20 \%$ & $10 \%$ & $90 \%$ \\
\hline
\end{tabular}

\section{REFERENCES}

Corlett EN and Bishop RP.1976. A Technique for Assessing Postural Discomfort. Ergonomics 19(2): 175-182

Garrow J. 1987. Human Nutrition and Dietetics. Nutrition News 1991. National Institute of Nutrition, Hyderabad.

Hasalkar S, Budihal R, Shivalli R and Biradar N.2004. Assessment of work load of weeding activity in crop production through heart rate. J. Hum. Ecol. 14(3): 165-167.

Hume R. 1966. Prediction of lean body mass from height and weight. J. Clinical Path. 19.

Kumar R, Singh RP, Singh NP and Vasisht AK. 2005. Production performance of maize crop in northern India: A district wise exploration. Agricultural situation in India LXI (11): 765-771.

Meyers JM, Miles J A, Faucett J, Janowitz I, Tejeda D G and Kabashima J N. 1997. Ergonomics in Agriculture: Workplace Priority Setting in the Nursery Industry. American Industrial Hygiene Association Journal 58:2: 121-126.

Nag PK and Chatterjee S K. 1981. Physiological Reactions of Female Workers in Indian Agricultural Work. Human Factors 23(5):607-614.

Potdar RR, Ram R, Kumar A, Singh JK and Mani I. 2011. Ergonomic proportion of the farm women experienced hand pain $(70 \%)$, finger injury $(70 \%)$ and palm injury $(80 \%)$ while working with OMS tool the levels of these pains reduced to 40,0 and $10 \%$, respectively.

It was observed that hand shelling caused swelling of fingers of most of the subjects and some of them even had blisters on their fingers and palm. This type of symptoms was completely absent when shelling was done using OMS tool.

\section{CONCLUSIONS}

Manual maize shelling by hand is a tedious task which appears to be easy but poses potential musculoskeletal risks or hazards to the female worker involved in the task. Since, maize is grown as a cash crop in the region, the increased volume of workload was observed in maize shelling by hand harvest season. The present article reported on evaluation of anOMS tool made up of mild steel enclosure with four tapered fins riveted to its inner periphery. The OMS tool was introduced among the farm women of Bihar and was evaluated for its ergonomic and technical performance. The shelling capacity of the OMS tool was about three times more than that of hand-shelling. Compared to hand shelling, the OMS tool required only $30 \%$ of the time for shelling same quantity of cobs. The women farmers were very interested as the octagonal sheller reduced their drudgery significantly. In view of increasing labour charges, promotions of low cost and efficient tools like octagonal maize sheller enforce the promotion of such tools for larger population.

\section{ACKNOWLEDGMENT}

Authors sincerely acknowledge the Indian Council of Agricultural Research, New Delhi for financial support in conducting the present study under the project "CRP on Farm Mechanization and Precision Farming". The authors are also thankful to Dr. P.S. Tiwari, Lead Project Coordinator, CRP on FM, CIAE, Bhopal.

Evaluation of Rotary Power Input by Hand and Leg Muscles to Operate Farm Equipment. Journal of Agricultural Engineering 48(3): 8-16.

Schlich E, Schumm M and Schlich M. 2010. 3-D-Body-Scanals anthropometrisches Verfahren zur Bestimmung der spezifischen Körperoberfläche. Ernährungs Umschau. 57: 178-183. http://ecoursesonline.iasri.res.in/mod/page/view.php? id $=125404$

Singh A, Gautam US, Pannase S and Singh A. 2010. Ergonomic evaluation of farm women during maize shelling. Indian Res. J. Ext. Edu. 10(3): 41-43.

Singh AK, Singh AK, Kumar R, Prakash V, Sundaram PK and Yadav SK. 2017. Indian Cereals Saga: Standpoint and Way Forward. Journal of AgriSearch 4 (1): 1-10.

Singh SP and Gite LP. 2007. Ergonomical evaluation of a hand operated paddy winnower by women workers. Journal of Agricultural Engineering 44(4): 67-71.

Singh SP, Gite LP, Agarwal N and Majumder J. 2007. Technical bulletin no. CIAE /2007/128, Women friendly improved farm tools and equipment. Published by CIAE, Bhopal. 56 p.

Singh SP, Gite LP, Majumder J and Agarwal N.2008. Aerobic capacity 
of Indian farm women using sub-maximal exercise technique on treadmill. Agricultural Engineering International: the CIGR ejournal MES 08001 . Vol. X.

Singh SP, Singh P and Singh S. 2011. Status of Maize Threshing in India. Agricultural mechanization in Asia, Africa, and Latin America 42 (3):21-28.

Tripathi SP, Somvanshi SPS, Bhadhoria UPS and Singh A. 2016. Ergonomic evaluation of hand operated maize sheller on farm women of Mandsaur district (M.P.), India. Plant Archives 16(1): 303-305.

Varghese MA, Saha PN and Atreya N. 1994. A rapid appraisal of occupational workload from modified scale of perceived exertion. Ergonomics 37(3): 485-491.

Verma S, Bajpai D, Shrivastava AK and Dhakad SS.2016. Effect of maize sheller on efficiency and ergonomic parameters for

Citation:

Sarkar B, Sundaram PK, Anurag AP, Kumar R, Kumar U, Rahman A and Upadhyaya A. 2021. Ergonomic evaluation of hand operated maize sheller for reducing drudgery of farm women in Bihar. Journal of AgriSearch 8(1):30-34 